\title{
The Effects of Rotation and Positional Change of Stump Tissues upon Morphogenesis of the Regenerating Axolotl Limb ${ }^{1,2}$
}

\author{
Bruce M. Carlson \\ Hubrecht Laboratory, de Uithof, Utrecht, The Netherlands, and Department of Anatomy, University of \\ Michigan, Ann Arbor, Michigan $48104^{3}$
}

Accepted July 9, 1975

\begin{abstract}
Rotation of a skin cuff $180^{\circ}$ around the proximodistal axis of the upper arm in the axolotl results in the formation of multiple regenerates in about $80^{\circ}$ of cases after amputation of the limb through the rotated skin. Rotation of the dermis or the flexor and extensor muscles folowed by amputation produced similar percentages of multiple regenerates. Rotated bone produced no abnormalities, and rotated stump epidermis was minimally effective in stimulating multiple regeneration. A thin strip of normally oriented skin interposed between a rotated skin cuff and the amputation surface blocks the morphogenetic effect of the rotated stump skin whereas removal of the normal skin between a rotated proximal skin cuff and the amputation surface allows the formation of a low percentage of multiple regenerates. Gross rotation of stump tissue components can be broken down into axial rotation per se and positional dislocation. Experiments conducted upon skin and muscle have shown that positional dislocation along the anteroposterior axis rather than axial rotation is the manipulation that leads to the formation of multiple regenerates. The first morphological indication of multiple regeneration is the appearance of a triaxial apical ridge on the blastema. Subsequently, digits form along the apical ridges.
\end{abstract}

\section{INTRODUCTION}

Among the strategies used to investigate morphogenetic control mechanisms in limbs, the experimental production of multiple regenerates has proven to be particularly useful because a well defined manipulation leads to an obvious morphological disturbance. One such manipulation is rotation of the skin covering the limb stump. Several investigators have independently discovered that various rotations of skin around limb stumps result in the formation of highly abnormal regenerates (Droin (1959), Rahmani (1960) in Triturus cristatus; Glade (1957), Settles (1967) in T. viridescens; Lheureux (1972) in Pleurodeles waltlii and Carlson (1974) in Ambystoma mexicanum). These papers have concentrated primarily upon documenting the phenomenon of multiple regeneration resulting from skin rotation, but some

1 Presented earlier in abstract form (Carlson, 1975a)

2 Supported by a grant from the Muscular Dystrophy Associations of America.

${ }^{3}$ Present address. early steps toward analysis of the morphogenetic mechanisms have been made.

This report describes experiments designed to answer three questions fundamental to our understanding how multiple regeneration is produced by the rotation of stump tissues: (1) What tissues of the limb stump have the capacity to cause multiple regeneration after rotation? (2) Must the rotated tissues be present at the level of the amputation surface? (3) Is axial rotation per se or the positional displacement that invariably accompanies gross rotation the critical manipulation in the stimulation of multiple regeneration?

\section{MATERIALS AND METHODS}

All experiments were conducted upon the forelimbs of axolotls (Ambystoma mexicanum) from the colonies at the Hubrecht Laboratory or the University of Michigan. The animals were anesthetized with 1:1000 MS 222 (Sandoz). Postoperatively they were returned to individual containers and fed three times per week with beef liver or heart. The experimental ani-

Copyright (C) 1975 by Academic Press, Inc.

All rights of reproduction in any form reserved. 
mals ranged in length from 70 to $250 \mathrm{~mm}$, each group being composed of animals of the same size. Control experiments upon a large number of animals have shown that within this range of lengths, the regenerative reactions to tissue rotation or displacement are both qualitatively and quantitatively alike. Both the design and special techniques used in individual experiments are presented together with the results.

Histological sections from selected amputated arms were stained with hematoxylin and eosin in order to determine the condition of the operated tissues at the time of amputation. This is particularly important for experiments involving muscle and bone. Occasional regenerates from various groups were fixed for histological examination, particularly if abnormalities were noted during the blastemal period. The experimental limbs were examined with a dissecting microscope at irregular intervals throughout the regeneration process.

About $80 \%$ of the mature regenerates were prepared as whole mounts, and the cartilage was stained by the Victoria blue $B$ method described by Bryant and Iten (1974). Other mature regenerates were serially sectioned for analysis of the muscle morphology. Because the types of multiple regenerates and their skeletal pattern did not differ substantially from those described previously (Carlson, 1974), only a brief morphological summary will be included in this paper.

\section{RESULTS}

\section{What Tissues of the Limb Stump Have} the Capacity to Cause Multiple Regeneration after Axial Rotation?

This series of experiments was initially designed to determine whether the morphogenetic influence residing in rotated skin (Carlson, 1974) could be assigned to either the epidermis or the dermis. It was then extended to other manipulable tissues of the limb stump. The basic experimental design consisted of rotating one tissue around the proximodistal (Pr-Ds) axis of the limb stump without altering the positions of any of the other tissues of the stump.

Dermis. In order to obtain a pure piece of dermis for rotation, cuffs of skin taken from the upper arm were soaked in 1:1000 Versene (Nutritional Biochemicals Corp.) in $0.6 \% \mathrm{NaCl}$ for $15 \mathrm{~min}$ at $21^{\circ} \mathrm{C}$. The epidermis loosened from the dermis, but it had to be mechanically removed by scraping the skin with a fine bent needle. Histological serial sections were used to verify the completeness of epidermal removal. In preliminary experiments, the epidermis was removed by soaking the skin in 1:1000 trypsin. Trypsinized epidermis came off in large sheets, but the percentage of successful dermal transplants was very low.

Series 1 (Control). In 16 upper arms of animals 194-238 $\mathrm{mm}$ long the skin was removed and the epidermis was scraped off after Versene treatment as described above. The dermis was sutured onto the limb in normal orientation. The cuff of dermis was allowed to heal for 9 days. During this time it became covered by normally oriented epidermis, which migrated from the neighboring skin. Each arm was amputated through the distal end of the dermal cuff. All 16 limbs (100\%) produced normal regenerates, demonstrating that Versene treatment of skin itself does not lead to the formation of multiple regenerates.

Series $2.180^{\circ}$ rotation (A-P, D-V) of the dermal cuffs (Fig. 1). In 11 animals (161$205 \mathrm{~mm}$ ) the skin of the right upper arm was removed and rotated $180^{\circ}$ as a control. On the left arms, the epidermis was removed from the skin cuffs with Versene, and the cuffs of dermis were replaced in a $180^{\circ}$ rotated position. A healing period of 7 days followed. This allowed the rotated dermal cuffs to be covered by normally oriented epidermis. Both arms were then amputated through the rotated skin or dermis. Of the limbs bearing rotated dermis, $81.8 \%$ produced multiple regenerates (Fig. 2) with a mean of 8.5 digits per multiple 
regenerate in comparison with $80 \%$ of the right control limbs (mean of 9.0 digits/multiple regenerate). The range of multiple digits in this experiment is shown in Table 1. One of the right control limbs was invalid for tabulation. This experiment demonstrates that rotation of dermis alone stimulates a frequency of multiple regeneration typical of stumps bearing rotated full thickness skin.

Epidermis. It has not been technically possible to obtain sheets of epidermis that could be rotated and maintained in position over a denuded dermis. In addition, it
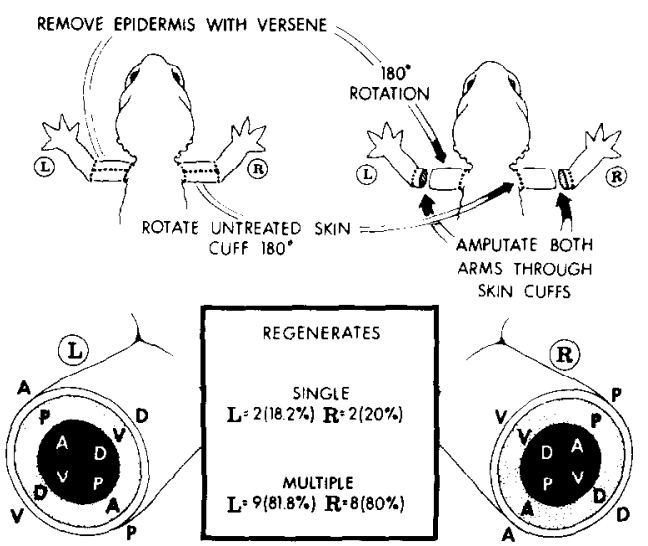

FIG. 1. Design and summary of the results of experiments involving the rotation of stump dermis.

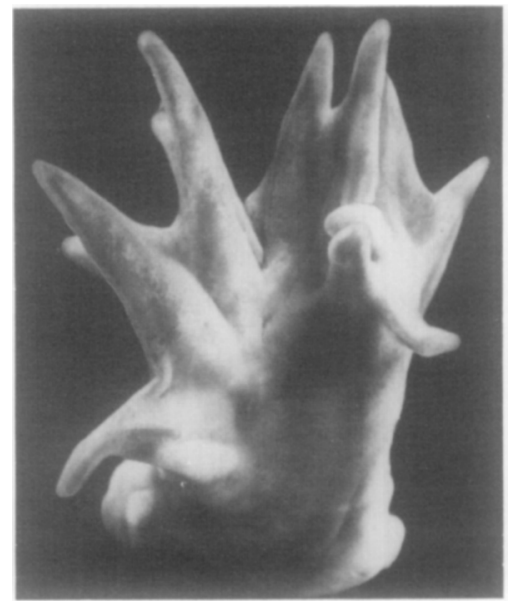

FIG. 2. Thirteen-digit left regenerate 6 months after $180^{\circ}$ rotation of stump dermis following removal of the epidermis with Versene. Viewed from posterodorsal aspect. is exceptionally difficult to exclude the migration of normally oriented epidermis over or under a rotated epidermis in long term experiments. Therefore, the direct method of rotating epidermis was bypassed in favor of a seemingly less direct technique. Creation of a limb stump bearing $180^{\circ}$ rotated epidermis alone was obtained in a two stage operation (Fig. 3). In

TABLE 1

Distribution of Multiple Digits in Experiments Designed to Determine the Ability of Tissue Components of the Limp Stump to Stimulate Multiple Regeneration (Group I)

\begin{tabular}{|c|c|c|c|c|c|}
\hline $\begin{array}{l}\text { No. of dig- } \\
\text { its }\end{array}$ & $\begin{array}{c}\text { Full } \\
\text { thick- } \\
\text { ness } \\
\text { skin } \\
\text { cuff } \\
\text { (Se- } \\
\text { ries } 2 \text {, } \\
\text { con- } \\
\text { trol) }\end{array}$ & $\begin{array}{l}\text { Der- } \\
\text { mal } \\
\text { cuff }\end{array}$ & $\begin{array}{l}\text { Epi- } \\
\text { der- } \\
\text { mal } \\
\text { cuff }\end{array}$ & $\begin{array}{l}\text { Mus- } \\
\text { cle (Se- } \\
\text { ries 1) }\end{array}$ & $\begin{array}{l}\text { Mus- } \\
\text { cle (Se- } \\
\text { ries 3) }\end{array}$ \\
\hline 5 & & 1 & & & 2 \\
\hline 6 & & 2 & & & 1 \\
\hline 7 & 2 & 1 & & 3 & 3 \\
\hline 8 & 1 & 1 & 1 & 4 & 2 \\
\hline 9 & 1 & 1 & & 2 & \\
\hline 10 & 3 & 1 & & 3 & \\
\hline 11 & 1 & & & & \\
\hline 12 & & & & 1 & \\
\hline 13 & & 2 & & 1 & \\
\hline 14 & & & & 1 & \\
\hline 15 & & & & 1 & \\
\hline Total & 8 & 9 & 1 & 16 & 8 \\
\hline $\begin{array}{l}\text { Mean } \\
\text { No. of } \\
\text { digits }\end{array}$ & 9.0 & 8.5 & 8.0 & 9.7 & 6.6 \\
\hline
\end{tabular}

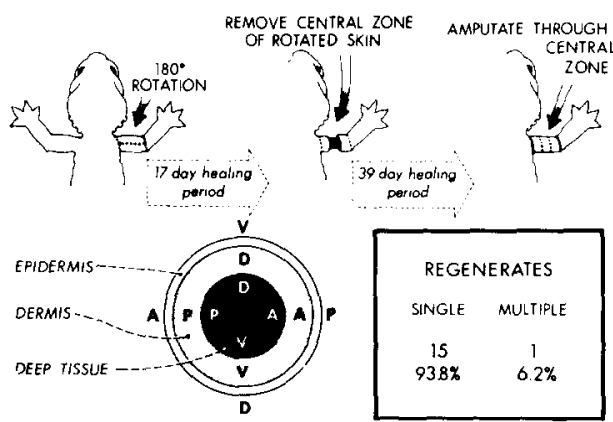

FIG. 3. Design and summary of the results of experiment involving $180^{\circ}$ rotation of stump epidermis. 
large animals (200-240 $\mathrm{mm}$ ) a longer than normal skin cuff $(8-9 \mathrm{~mm})$ was rotated $180^{\circ}$ (A-P and D-V reversal) in each upper arm. An 18-day period was allowed for the skin cuffs to heal firmly in place and for epidermal migration to cease. Then in each arm a smaller cuff (4-5 $\mathrm{mm}$ ) was removed from the center of the original large cuff. Two to two and a half millimeters of rotated skin remained on either side of the central skin defect. The wound created by removal of the smaller skin cuff was allowed to heal for 37 days. During this time the defect was first healed in by epidermis migrating in from the surrounding rotated cuff tissues. A new dermis eventually formed beneath the migrated epidermis. The new dermis in wounds of this type has normally been assumed to be of local origin, but the migration of cells from the dermis of the surrounding rotated skin cannot be excluded. After the second healing period, the limbs were amputated through the level of the newly regenerated skin containing rotated epidermis. One $(6.2 \%)$ of the experimental limbs produced a multiple regenerate ( 8 digits), and the other 15 regenerates $(93.8 \%)$ were normal.

When viewed in conjunction with the experiments involving dermal rotation, this experiment is interpreted to show that rotated stump epidermis has little, if any, ability to stimulate the formation of multiple regenerates. In this experiment there are two major options for explaining the multiple regenerate that did form. One is that rotated epidermis may occasionally exert a morphogenetic influence. The other is that the multiple regenerate was stimulated by cells migrating into the regenerating dermis from the rotated skin cuffs on either side of the central skin defect.

Bone. Series 1. In 20 limbs of axolotls 87-100 $\mathrm{mm}$ in length, the humerus was removed, rotated $180^{\circ}$ (A-P, D-V reversal) and replaced immediately in its normal location within the unamputated limb. Humeral extirpation was easily accomplished by making a small slit in the skin near the elbow on the extensor side of the limb. The distal end of the bone was dissected free with the tip of a No. 5 microforceps. The diaphysis of the bone was grasped with forceps and the entire bone was removed by a sharp jerk. After a 12-day healing period, each limb was amputated through the level of the rotated bone (Fig. 4). All 20 limbs produced normally oriented and normally formed four-digit regenerates.

One possible reason for normal regeneration in this series was the potential rerotation into normal axial positions of cells released from the rotated bones. Correction of axial position by the rerotation of experimentally rotated organ primordia has been observed in limb buds (Harrison, 1921). To eliminate the possibility of a correction of axial relationships by rerotation, humeri were exchanged between contralateral limbs.

Series 2. In 19 axolotls $71-85 \mathrm{~mm}$ long the right and left humeri were exchanged so that in the left arms the A-P axes of the bones were reversed and in the right arms the $\mathrm{D}-\mathrm{V}$ axes were reversed. After a 7-day healing period, the arms were amputated through the rotated bones (Fig. 5). All regenerates on both limbs were normal.

Series 3. Heteropleural transplants of humeri with A-P axial rotation were also performed on 18 young Triturus alpestris (50-55 mm long). Following healing of the bones and limb amputation, 17 limbs pro-

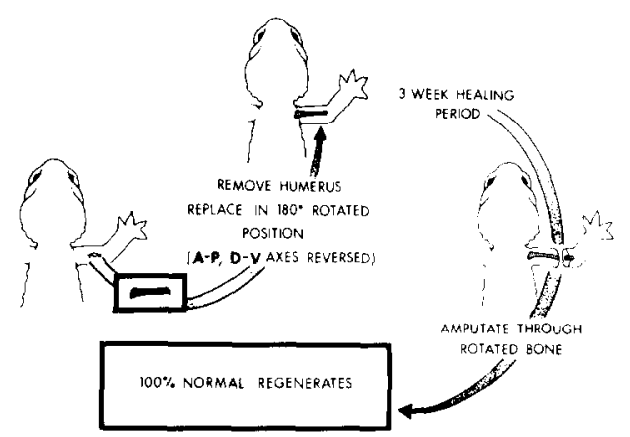

Fig. 4. Design and summary of the results of experiment involving $180^{\circ}$ rotation of the humerus within the stump. 


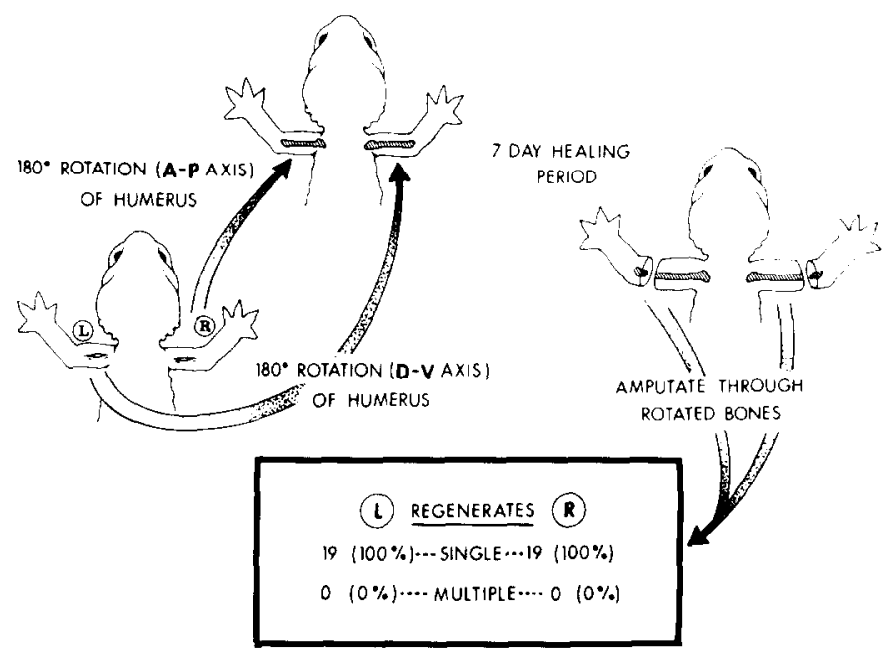

Fig. 5. Design and summary of the results of experiment involving heteropleural transplantation of humeri within the stump (A-P or D-V reversal).

duced normal regenerates and one produced a blunt spikelike structure.

These experiments demonstrate that within the limits of the species used, the age of the animals and the experimental design, rotation of bone within the limb stump does not affect the morphogenesis of the regenerate.

Muscle. Series 1. In 20 limbs of animals 100-120 mm long a muscle rotation experiment was performed. It consisted of removing the bulk of the flexor and extensor muscles of the upper arm, cross-transplanting the flexor in place of the extensor (and vice versa) and concomitantly rotating the muscles so that their A-P and D-V axes were $180^{\circ}$ reversed with respect to those of the limb (Fig. 6). Most of the anconeus muscle was removed from the extensor side and the humeroantibrachialis was removed from the flexor side. The coracobrachialis longus muscle was left intact. The transplanted muscles were allowed to heal for 19 days before the arms were amputated through the muscles. Histological preparations revealed that the majority of the muscle fibers within the transplants at the time of limb amputation were very thin and had central nuclei. This is compatible with the degeneration and subse-

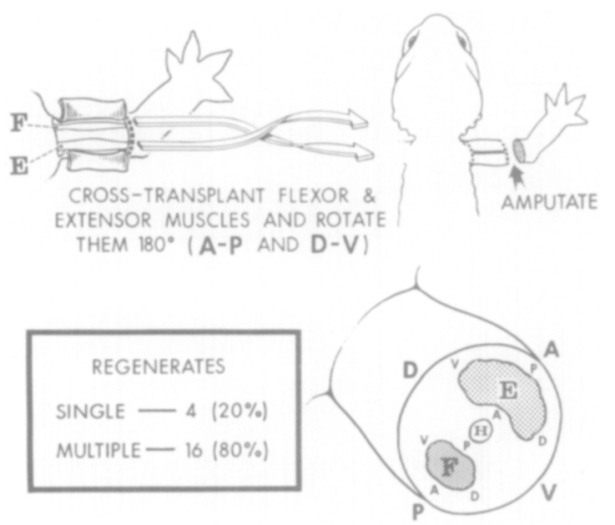

FiG. 6. Design and summary of the results of experiment involving cross-transplantation and concomitant $180^{\circ}$ axial rotation of stump muscles.

quent regeneration of most of the muscle fibers within the transplants.

Of the 20 regenerates, $4(20 \%)$ were normal and $16(80 \%)$ were multiple (Fig. 6). The multiple regenerates were very complex, averaging 9.7 digits per limb (Fig. 7; Table 1).

Series 2 . As a control for multiple regeneration induced by damage alone, flexor and extensor muscles in 10 upper arms of $120-130 \mathrm{~mm}$ axolotls were removed as in Series 1 and replaced in their normal position. After 13 days, the arms were ampu- 
tated. All 10 limbs produced normal fourdigit regenerates.

Series 3. A second experiment involving muscle rotation was performed to determine whether or not rotated muscles retain their morphogenetic information for extended periods of time. In 10 limbs of $130-\mathrm{mm}$ animals, the flexor and extensor muscles were rotated as described for Series 1. Four months were allowed to elapse between rotation and subsequent amputation of the limbs (Fig. 8). Eight (80\%) of these limbs produced multiple regenerates whose complexity (mean of 6.6 digits) was less than that of those in the preceding series (Table 1). The remaining two limbs (20\%) were normal.

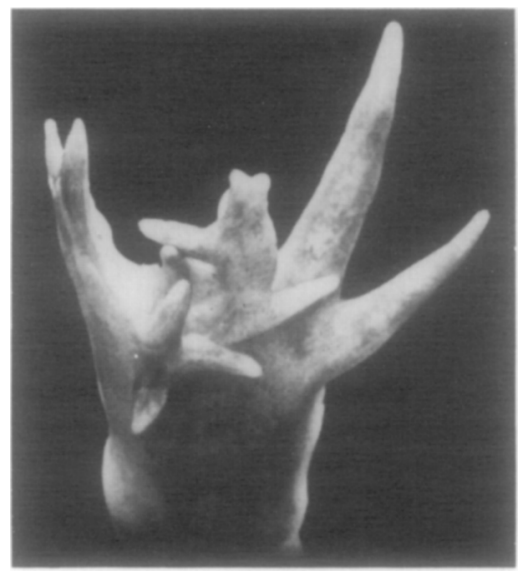

Fig. 7. Fourteen-digit right regenerate 5 months after rotation of flexor and extensor muscles within the limb stump. Viewed from dorsal aspect.

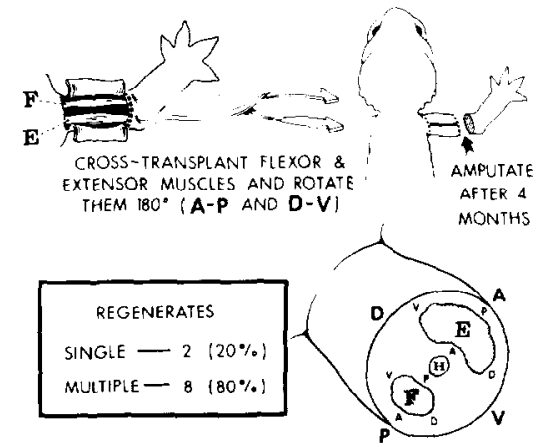

FIG. 8. Design and summary of the results of experiment involving rotation of limb muscle and amputation 4 months later.
Nerve. Nerve rotation experiments were not performed because no reliable method was found for ensuring that a rotated nerve would remain rotated.

In summary, rotated dermis and muscle within the limb stump exert a profound morphogenetic effect upon the regenerating limb. Rotated bone is without effect, and rotated epidermis is minimally, if at all, effective. Nerve could not be accurately rotated.

II. Must the Rotated Tissue be Present at the Level of the Amputation Surface in Order to Exert Its Morphogenetic Effects?

Epimorphic regeneration is normally conceded to be a local process, involving cells located within 1-2 mm of the plane of amputation (Butler, 1935). The early work in this area was concerned primarily with localizing the cells that contribute to the regeneration blastema. Whether or not the limb stump can exert morphogenetic effects from a greater distance is not so clear. The experiments described below were designed to determine the morphogenetic effects of rotated skin separated from the amputation surface by a distance of at least $2 \mathrm{~mm}$. In one variation, normal skin intervened between the rotated skin and the amputation surface, and in the other, the intervening skin was removed between the rotated skin and the end of the stump. While these experiments were in progress, Lheureux (1972) reported that normal skin located between a rotated skin cuff and the amputation surface blocked the morphogenetic effect of the rotated skin in Pleurodeles.

The effect of normal skin located between rotated skin and the amputated surface (Fig. 9). In 10 limbs of large animals $(203-236 \mathrm{~mm})$ the skin covering the proximal half of the upper arm was rotated $180^{\circ}$ in the usual manner. After a 6-day healing period the limbs were amputated through normal skin 1-2 mm distal to the rotated skin. All 10 of the limbs produced normal 


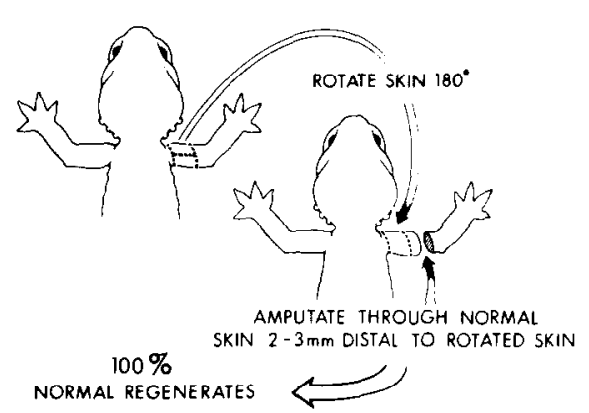

Fig. 9. Design and summary of the results of experiment involving the interpolation of normally oriented skin between a rotated skin cuff and the amputation surface.

regenerates, thereby confirming the report of Lheureux (1972).

Removal of skin between a rotated skin cuff and the amputation surface. The previous experiment left little doubt that normal skin interposed between a rotated skin cuff and the amputation surface blocks the morphogenetic effect of the rotated skin. The next experiment was designed to determine the degree to which rotated skin, separated from the amputation surface by several millimeters, could influence morphogenesis of the regenerate in the absence of intervening normally oriented skin. The animals used were 120 $145 \mathrm{~mm}$ long.

Series 1 (control). The skin from the proximal half of 10 arms was removed and replaced in normal orientation. After a 2week healing period the limbs were amputated $3 \mathrm{~mm}$ distal to the end of the skin cuff. At the time of amputation all normal skin between the cuff and the amputation surface was removed. Nine (90\%) of the ten limbs produced normal regenerates. In the tenth regenerate the last phalanx of the second digit was forked. Although forked digits occur rarely in regenerates arising after simple amputation, the occurrence of one multiple regenerate in this control series suggests that there may be some morphogenetic instability resulting from the surgical manipulation alone.

Series 2. Rotation of a proximal skin cuff and removal of the skin distal to it at the time of amputation (Fig. 10). In 15 experimental and 10 control limbs the proximal skin of the upper arm was removed, rotated $180^{\circ}$ (D-V and A-P axial reversal) and allowed to heal for 2 weeks. The control limbs were amputated through the level of the rotated skin. Experimental limbs were amputated $3 \mathrm{~mm}$ distal to the end of the rotated cuff, and all skin between the rotated cuff and the amputation surface was removed.

The denuded ends of the experimental limbs became epithelialized within 2 days. The rate of epithelialization alone suggested that the initial wound epidermis came from the rotated proximal skin cuff rather than unrotated shoulder skin. Most experimental limbs underwent a slight resorption, but in all cases at least $2 \mathrm{~mm}$ remained between the distal part of the rotated skin cuff and the end of the limb stump. During the preblastemal period the contours of the limb stumps differed from those of normal stumps. For the first 2-3 weeks the ends of the stumps were often irregular. As a new dermis formed beneath the epidermis, the irregularities were smoothed out. The originally denuded portions of the stumps went through a phase during which they were

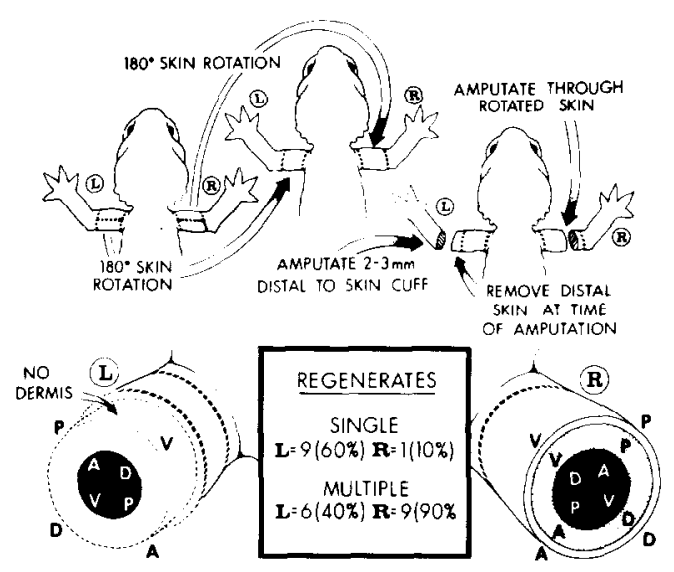

FIg. 10. Design and summary of the results of experiments involving the $180^{\circ}$ rotation of a proximal skin cuff and the removal of $2-3 \mathrm{~mm}$ of skin between it and the wound surface at the time of amputation. 
more bulbous than is normal for the axolotl. This condition commonly persisted through the early and midblastemal stages and was seen in the previous stages as well.

Of the 15 experimental regenerates, 9 $(60 \%)$ were normal and $6(40 \%)$ were multiple, averaging 6.5 digits per regenerate (Table 2). Five of these multiple regenerates were of the usual variety, consisting of irregularly arranged groups of digital and carpal elements. This type was called "expanded regenerates" by Iten and Bryant (1975), although there are important enough differences in morphology so that the axolotl multiple regenerates cannot be confined to Iten and Bryant's definition. The other multiple regenerate was a four-digit limb arising from a separate fo-

TABLE 2

Distribution of Multiple Digits in Experiments Designed to Determine Whether or NOT Rotated Tissue Must Be at the Amputation Surface to Stimulate Multiple Regeneration (Group II)

\begin{tabular}{|c|c|c|c|c|}
\hline $\begin{array}{l}\text { No. of dig- } \\
\text { its }\end{array}$ & $\begin{array}{l}\text { Distal } \\
\text { skin re- } \\
\text { moval } \\
\text { only } \\
\text { (con- } \\
\text { trol, Se- } \\
\text { ries 1) }\end{array}$ & $\begin{array}{l}\text { Immedi- } \\
\text { ate re- } \\
\text { moval } \\
\text { of skin } \\
\text { distal to } \\
\text { rotated } \\
\text { cuff (Se- } \\
\text { ries 2) }\end{array}$ & $\begin{array}{l}\text { Amputa- } \\
\text { tion } \\
\text { through } \\
\text { rotated } \\
\text { skin cuff } \\
\text { (control, } \\
\text { Series 2) }\end{array}$ & $\begin{array}{c}\text { De- } \\
\text { layed } \\
\text { amputa- } \\
\text { tion } \\
\text { after } \\
\text { distal } \\
\text { skin re- } \\
\text { moval } \\
\text { (Series } \\
3 \text { ) }\end{array}$ \\
\hline 5 & 1 & 3 & 2 & 3 \\
\hline 6 & & & 3 & \\
\hline 7 & & 1 & & \\
\hline 8 & & 1 & 1 & \\
\hline 9 & & 1 & 1 & \\
\hline 10 & & & & \\
\hline 11 & & & & \\
\hline 12 & & & & \\
\hline 13 & & & & \\
\hline 14 & & & 1 & \\
\hline 15 & & & & \\
\hline Total & 1 & 6 & $8^{a}$ & 3 \\
\hline $\begin{array}{l}\text { Mean } \\
\text { No. of } \\
\text { digits }\end{array}$ & 5.0 & 6.5 & 7.4 & 5.0 \\
\hline
\end{tabular}

a One early multiple regenerate from this group was fixed for histology before digit formation was complete. It was not included in this tabulation. cus on the limb stump. This focus had been identified when the primary regenerate was in the mid- to late cone stage.

The occurrence of an intermediate percentage (less than $60 \%$ and over $10 \%$ ) of complex multiple regenerates was of interest because it had not been previously noted in over 40 experiments involving rotation of a full skin cuff. There were several possible interpretations, the three most likely being: (1) that in contrast to the conclusion made previously, rotated epidermis can cause the formation of multiple limbs, (2) that dermal cells from the rotated proximal skin cuff migrated beneath the distal wound epidermis and were exerting a morphogenetic effect directly at the amputation surface or (3) that the rotated skin cuff was able to exert a morphogenetic effect at a distance in the absence of an intervening cuff of normally oriented skin. The possibility of a distal migration of dermal cells from the rotated skin was of particular interest because a number of unusual results in regeneration experiments over the years have been reinterpreted on the basis of a migration of cells from more proximal regions to the distal end of the amputated limb. Distal cellular migrations are likely to be of greater magnitude in amputated than in nonamputated limbs. The following experiment was designed to eliminate or reduce the possibility and/or amount of cell migration from the dermis of the rotated skin cuff beneath the epidermis to the apex of the limb stump.

Series 3. Rotation of a proximal skin cuff, removal of skin distal to it, and amputation one month after distal skin removal (Fig. 11). In 14 arms of animals from the same mating as those used in Series 1 and 2 , skin from the proximal half of the upper arm was rotated $180^{\circ}$ and allowed to heal for 2 weeks. Then all skin between the distal border of the skin cuff and the wrist was removed. The animals were allowed to repair the skin defect for 30 days. During epithelialization of the denuded areas, vis- 


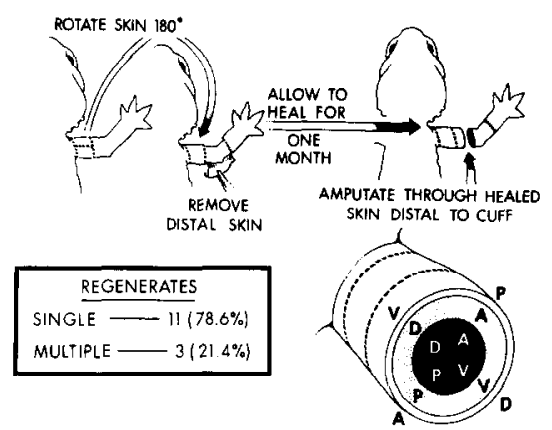

FIG. 11. Design and summary of the results of experiment involving the $180^{\circ}$ rotation of a proximal skin cuff, removal of skin distal to it and amputation 1 month later.

ual observation demonstrated that the distal upper arm was initially epithelialized by epidermis from the region of the rotated proximal cuff rather than by a proximal migration of normally oriented epidermis from the remaining skin of the hand and distal forearm. After the 30-day healing period, all limbs were amputated $3 \mathrm{~mm}$ distal to the end of the skin cuff.

Eleven (78.6\%) of the limbs produced normal four-digit regenerates. The remaining three (21.4\%) were multiple, averaging $\mathbf{5 . 0}$ digits per regenerate (Table 2). Each of the three multiple regenerates consisted of a terminal duplication of the fourth digit. These simple duplications are in contrast to those which formed in Series 2. Half of the latter were of the complex type commonly seen when rotated skin is present at the amputation surface.

\section{The Role of Axial Rotation per se us Positional Change of Stump Tissues as Related to the Formation of Multiple. Regenerates}

The gross manipulation of tissue rotation within a limb can be broken down into two components: (1) axial rotation of component cells and tissues with respect to the axes of the limb and (2) positional change alone. These two components can be fairly well, but not completely, separated experimentally. The following experiments demonstrate that positional change rather than axial rotation of tissues within the limb stump is responsible for the generation of multiple limb regenerates in this experimental model.

Muscle. As was demonstrated above (Figs. 6 and 8), cross transplantation of flexor and extensor muscles with concomitant axial rotation resulted in an $80 \%$ incidence of very complex multiple regenerates after amputation.

Series 1. Positional change of stump muscles without axial rotation (Fig. 12). In 20 upper arms, the intact flexor (humeroantibrachialis) and extensor (anconeus) muscles were cross-transplanted without axial rotation. To keep them in place, both ends of each transplanted muscle were sutured to the origin and insertion of the muscle in whose bed it was placed. The muscles were allowed to heal for 14 days before the limbs were amputated through the level of the transplanted muscles. Eighteen regenerates (90\%) were of the complex multiple type (mean of 7.1 digits/limb; Table 3; Figs. 13 and 14$)$, and two (10\%) were normal.

Series 2. Axial rotation of stump muscles in situ (Fig. 12). In 20 limbs the flexor and extensor muscles were removed, rotated $180^{\circ}$ (A-P and D-V axial reversal)

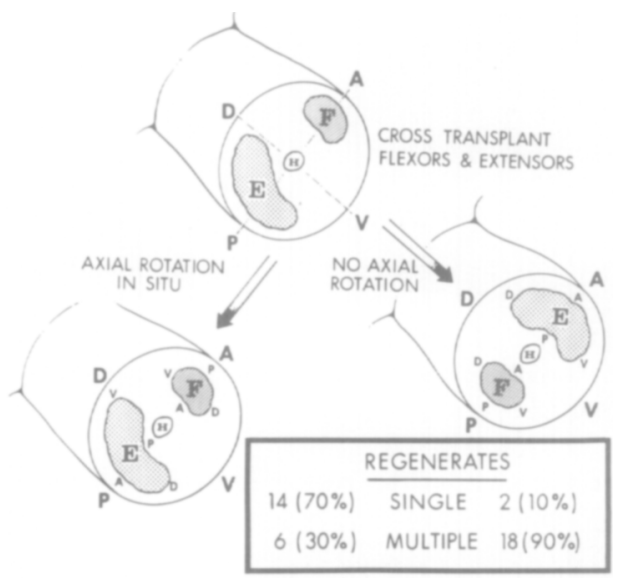

Fig. 12. Design and summary of the results of experiment in which the effects of axial rotation and positional change of stump musculature are separated. The upper diagram represents the normal unoperated limb. 
TABLE 3

Distribution of Multiple Digits in Experiments Designed to Determine the Role of Axial Rotation vs Positional Change in Stimulating Multiple Regeneration (Group III)

\begin{tabular}{cccccc}
\hline $\begin{array}{c}\text { No. of dig- } \\
\text { its }\end{array}$ & $\begin{array}{c}\text { Muscle } \\
\text { posi- } \\
\text { tional } \\
\text { change } \\
\text { (Series } \\
\text { 1) }\end{array}$ & $\begin{array}{c}\text { Muscle } \\
\text { axial } \\
\text { rota- } \\
\text { tion in } \\
\text { situ } \\
\text { ries } 2 \text { (Se- }\end{array}$ & $\begin{array}{c}\text { Nerve } \\
\text { posi- } \\
\text { tional } \\
\text { change }\end{array}$ & $\begin{array}{c}\text { Shoul- } \\
\text { der } \\
\text { skin } \\
180^{\circ} \text { ax- } \\
\text { ial rota- } \\
\text { tion }\end{array}$ & $\begin{array}{c}\text { Shoul- } \\
\text { der } \\
\text { skin po- } \\
\text { si- } \\
\text { tional } \\
\text { change } \\
\text { (A-P) }\end{array}$ \\
\hline 5 & 3 & 3 & 2 & & 3 \\
6 & 3 & 2 & 1 & 1 & \\
7 & 7 & 1 & 1 & 1 & 2 \\
8 & 1 & & & 1 & \\
9 & 2 & & & & \\
10 & & & & & 1 \\
11 & & & & & \\
12 & 1 & & & & \\
$\begin{array}{c}\text { Total } \\
\text { Mean }\end{array}$ & $17^{a}$ & 6 & 4 & 3 & 6 \\
No. of & 7.1 & 5.7 & 5.8 & 7.0 & 6.7 \\
digits & & & & & \\
\hline
\end{tabular}

${ }^{a}$ One early multiple regenerate from this group was fixed for histology before digit formation was complete. It was not included in this tabulation.

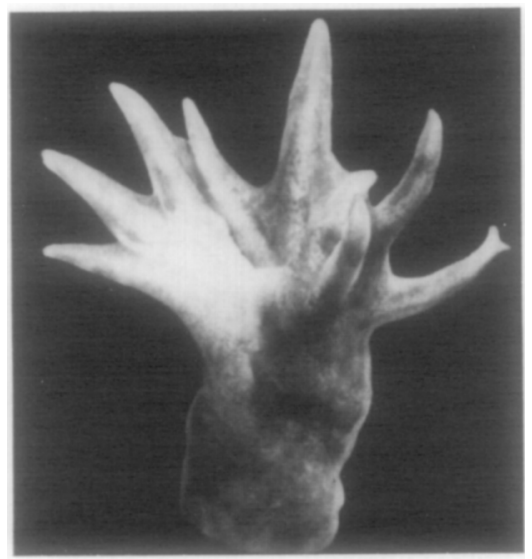

FIG. 13. Nine-digit regenerate 4.5 months after positionally dislocating the flexor and extensor muscles of the limb stump. Dorsal view.

and sutured into place to prevent rerotation. This procedure does not result in pure axial rotation because within the muscle rotated in situ there is necessarily a certain amount of positional change as well, although in this case the major dislocation is along the D-V axis, which in skin rota-

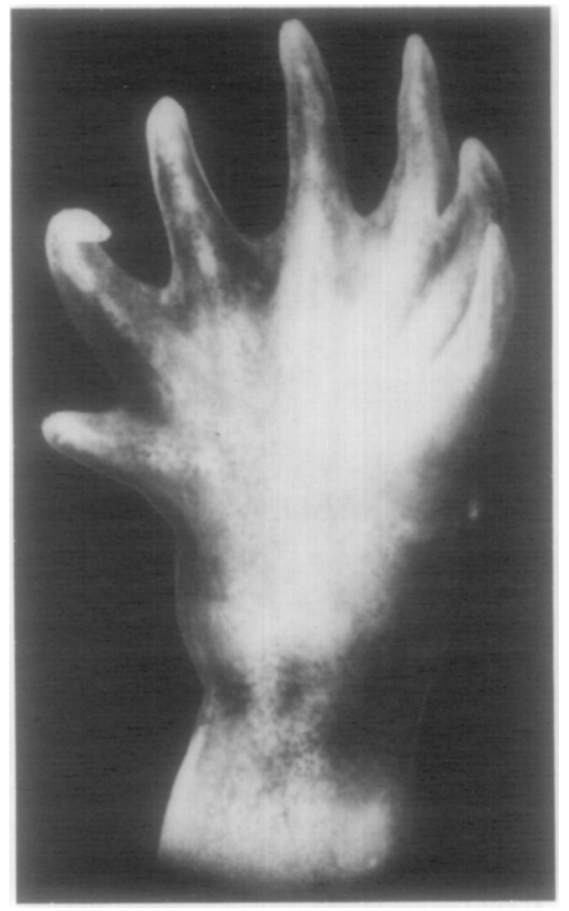

Fig. 14. Seven-digit regenerate 4.5 months after positionally dislocating the flexor and extensor muscles of the limb stump. Palmar view.

tion experiments does not result in the formation of multiple regenerates. Fourteen days later the limbs were amputated through the rotated muscles. Of the 20 regenerates, $14(70 \%)$ were normal and 6 (30\%) were multiple, averaging 5.7 digits per limb (Table 3).

Bone. Multiple regenerates never formed from stumps containing humeri that had been rotated in situ (Figs. 4 and 5). One option was that the amount of positional displacement involved in the rotation of a bone is small enough to be ineffective in producing a morphological abnormality. The other option was that bone, for some intrinsic qualitative or quantitative reason, is not capable of influencing morphogenesis if its normal position in the limb stump is disturbed. This experiment was designed to determine the effect upon the morphology of the regenerate of adding a positionally dislocated bone to the limb stump. 
In 20 four-month-old axolotls (66-78 $\mathrm{mm}$ ) the left humerus was transplanted between the anconeus muscle and the skin of the right arm (Fig. 15). This procedure allows maximal positional change of the bone along the A-P axis of the limb. After a 1-week healing period, the arms were amputated through the level of the diaphysis of the transplanted humeri. All of the 20 regenerates were normal, demonstrating that positional change of the humerus is not an adequate stimulus to elicit multiple regeneration.

Nerve. Although the nerves of the upper arm could not be accurately rotated with respect to the limb axes, positional change was possible. In 22 limbs the brachial nerve was deviated to a position between the anconeus muscle and the skin (Fig. 16). The limbs were amputated at the time

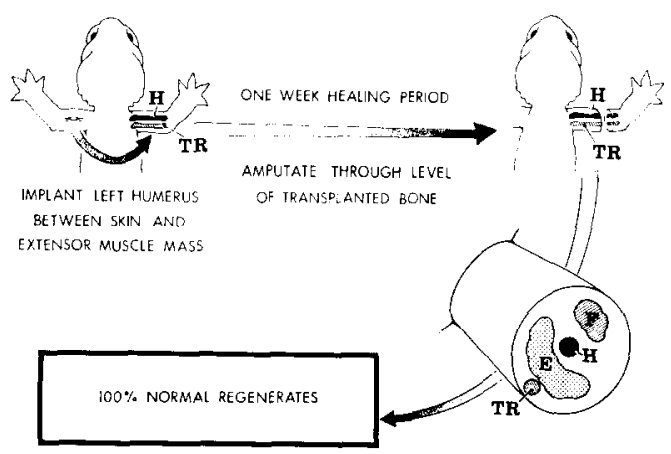

Fig. 15. Design and summary of the results of experiment involving the positional dislocation of a bone within the limb stump.

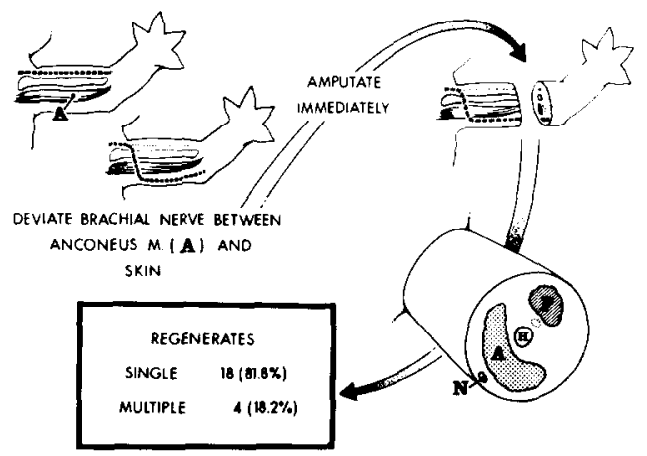

FIG. 16. Design and summary of the results of experiment involving the positional dislocation of a nerve within the limb stump. of nerve deviation. Eighteen (81.8\%) of the regenerates were normal and four (18.2\%) were multiple, averaging 5.8 digits per limb (Table 3). One of the multiple regenerates was a typical complex seven-digit regenerate in which the duplication originated at the carpal level. The other three regenerates were normal until the last phalangeal segments of the digits. In two of these the fourth digit was forked, and in the other both the first and fourth digits were forked.

Skin. Due to a shortage of animals with normal forelimbs, experiments involving positional dislocations of skin were performed on the shoulder and hind limb.

Because the shoulder is basically a two dimensional system, positional change of shoulder skin was easily accomplished. The arm was exarticulated at the shoulder, and a rectangle of skin 3 myomeres in length was removed around the point of exit of the arm (Fig. 17). On the right shoulder, each piece of skin was divided into an anterior and a posterior half. The anterior and posterior halves were exchanged without any axial rotation. Of 19 animals, 11 failed to regenerate. Six ( $75 \%$ ) of the eight limbs that regenerated were multiple, averaging 6.7 digits each. The remaining two regenerates ( $25 \%$ ) were hypomorphic, one with two and one with three digits. In contrast, only $37.5 \%$ of the contralateral control limbs in which similar pieces of shoulder skin were rotated $180^{\circ}$ (A-P and D-V rotation) produced multiple regenerates (mean of $7.0 \mathrm{digits} / \mathrm{limb}$; Table 3). Thus, on a small sample, positional change of shoulder skin without axial rotation was more effective in producing multiple limbs than was $180^{\circ}$ rotation.

Assessment of the effect of positional change of limb stump skin without concomitant axial rotation requires a more complex set of experiments in order to obtain interpretable results. The reasons for this are the three dimensional aspects of the limb and the fact that skin cannot be transplanted with the epidermis on the inside. 

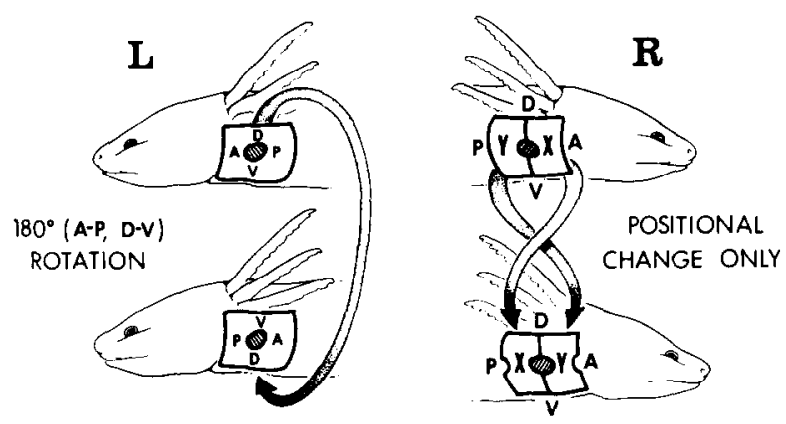

\begin{tabular}{|c|c|c|c|c|}
\hline \multicolumn{2}{|c|}{ LEFT } & REGENERATES & \multicolumn{2}{|c|}{ RIGHT } \\
\hline \multirow{4}{*}{ 180" ROTATION } & $3(42.9 x)$ & MULTIPLE & $6(75 \%)$ & \multirow{4}{*}{$\begin{array}{l}\text { POSITIONAL } \\
\text { CHANGE }\end{array}$} \\
\hline & $1(14.3 \%)$ & NORMAL & $0(0 \%)$ & \\
\hline & $3(42.9 \%)$ & HYPOMORPHIC & $2(25 \%)$ & \\
\hline & $0-=$ & NO REGEN. & $10-$ & \\
\hline & 13 & TOTAL & 18 & \\
\hline
\end{tabular}

FIG. 17. Design and summary of the results of experiments involving the positional dislocation of shoulder skin.

In the hind limbs of axolotls, strips of skin representing one quadrant of the limb were removed; the epidermis was removed with Versene; the remaining dermal strips were implanted beneath hind limb skin so that positional dislocation alone or positional dislocation plus axial rotation was accomplished. Preliminary observations on a series of 80 limbs have shown that in the hind limb positional change of dermis alone produces a percentage of multiple limbs equivalent to that resulting from positional change plus axial rotation of a dermal strip.

\section{Morphological Observations}

The multiple regenerates produced in these experiments all fell within the same spectrum of morphological types described previously (see Carlson, 1974). As can be seen from Tables 1-3, the multiple regenerates possessed from 5 to 15 digits. The most complex regenerates tended to begin with duplications in the zeugopodial segment. Duplications of the radius and/or ulna were sometimes complete, but at other times the distal half of the bone was forked. Distal to these duplications, the carpal elements and digits were correspondingly multiple. In other less complex regenerates extra skeletal elements did not appear until the carpal level, and in the simplest multiple regenerates only the terminal phalanx of a digit (usually the fourth) was duplicated.

Except for regenerates arising from the shoulder level, in which at times two separate limbs arise, the multiple regenerates seen in these experiments were grossly single structures in the zeugopodium. As a rule, gross duplication was only seen at the phalangeal and metacarpal levels. Except for the simple five-digit regenerates, in which duplication tended to occur on the fourth digit, there was no consistent localization of the multiple structures in any experiment. In these experiments no regenerates with longitudinal duplications of limb segments were observed.

The wide range of complexity of multiple regenerates within a single experiment leads one to conclude that there is no single time during which the morphogenetic misinformation is expressed within the regenerating limb, but rather that this expression can occur over a prolonged span of time.

One observation made repeatly during these experiments appears to be of significance in delineating the pathway and 
mechanism of information transfer from the limb stump to the outgrowing regenerate. In 36 limbs, blastemas at the late cone stage or beyond were characterized by the presence of a prominent triaxial ridge that was easy to see with a dissecting microscope. Regenerates possessing triaxial ridges always developed into multiple structures, and the degree of complexity was correlated with the time of appearance and the arrangement of the triaxial ridges.

Three variants of triaxial ridge structure will be illustrated here (Fig. 18). None of these variants is unique to any particular experiment. The first type consists of three components of approximately the same size, each being roughly $120^{\circ}$ removed from the next (Fig. 18A). In the specific case illustrated here (Figs. 18A and 19), the flexor and extensor muscles of the stump were both cross-transplanted and axially rotated. A prominent triaxial ridge had formed by 29 days after amputation. Three digits formed along each of the three components of the ridge (Fig. 19). Two of the clusters were obviously dominant centers whereas the third was an irregular cluster of smaller digits.

The second, and more common, type is a triaxial ridge containing two major ridge components and a minor one (Fig. 18B). The two major ridge components usually

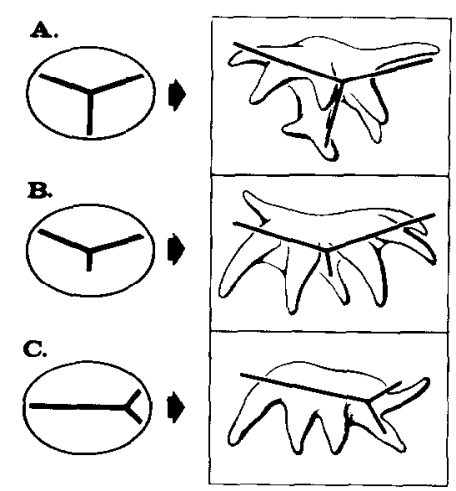

FiG. 18. Scheme of variants of the triaxial ridge found on the blastemas of multiple regenerates and the morphology of late regenerates arising from them. meet at an angle of from 140 to $170^{\circ}$. The minor ridge commonly extends a short way past the point of fusion of the major ridges. The angles between the minor ridge and each major ridge are approximately equal. Normally three to four digits will form along each major ridge and one or possibly two digits will grow out from the minor ridge (Fig. 20).

The third variant is seen during the paddle stage, often when primordia of the first two to three digits are already visible. The ridge consists of a "Y"-shaped bifurcation postaxial to the newly formed digital primordia (Fig. 18C), and it gives rise to a duplicated fourth digit (Fig. 21). Figure 22 shows a histological cross-section through a regenerate possessing a late-forming

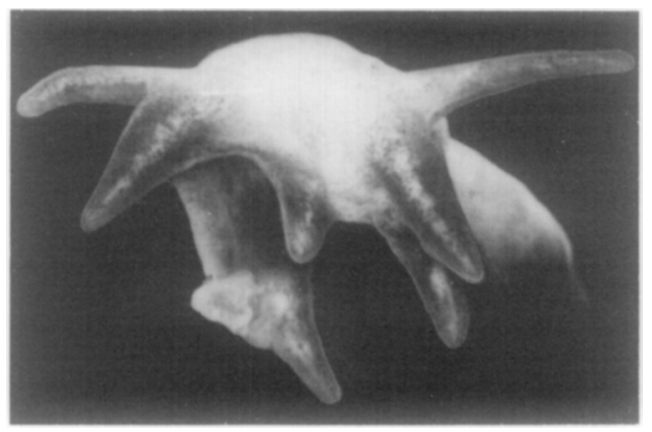

FIG. 19. Nine-digit left regenerate 5.5 months after the rotation and cross-transplantation of stump muscle in a $115 \mathrm{~mm}$ axolotl. Illustrated in Fig. 18A.

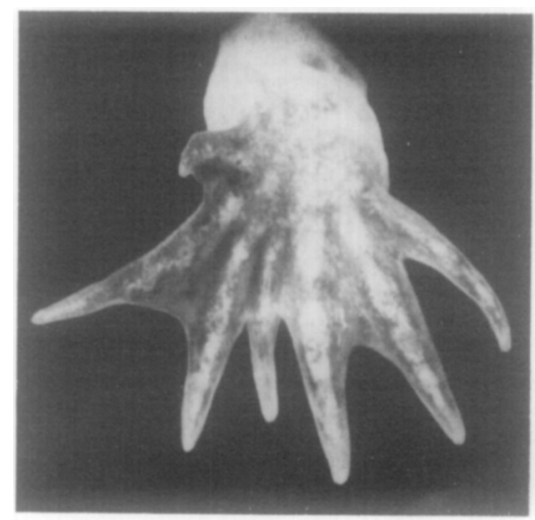

FIG. 20. Seven-digit left regenerate 5.5 months after the rotation and cross-transplantation of stump muscle. Illustrated in Fig. 18, B. 
triaxial ridge of the type illustrated in Fig. $18 \mathrm{C}$.

In an ongoing study of normal limb regeneration in the axolotl (Carlson, Connelly and Tank), a pronounced ridge has been seen running along the edge of the flattening blastema in a pre- to postaxial direction. This ridge, which on the postax-

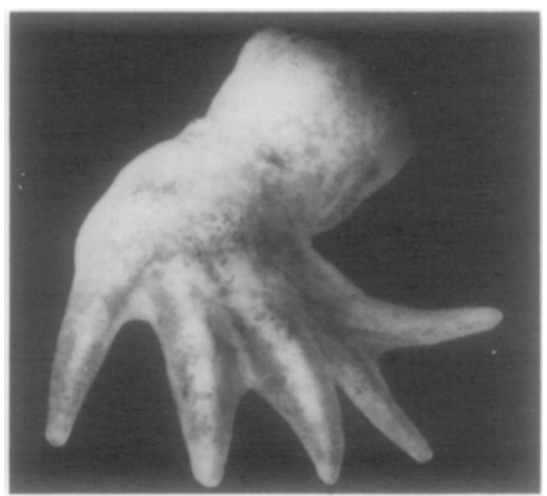

Fig. 21. Five-digit left regenerate 4.5 months after the rotation and cross-transplantation of stump muscle. Illustrated in Fig. 18C. ial side of the blastema often extends proximally to the base of the regenerate, persists during the stages when digital primordia appear and regresses as the digits begin to elongate.

The relationship between the triaxial ridge and the formation of multiple regenerates from stumps bearing rotated or positionally dislocated tissues is still under investigation. At this point it is certain that digits will form along the ridge areas in both normal and in multiple regenerates, and the appearance of a triaxial ridge is the earliest absolute indication that a regenerate will be multiple. At this time it is not yet known whether the ridge stimulates the formation of digits or whether it is merely an indication of impending digit formation in the axolotl.

\section{DISCUSSION}

The primary purpose of this discussion will be to summarize the present status of our knowledge about the transmission of

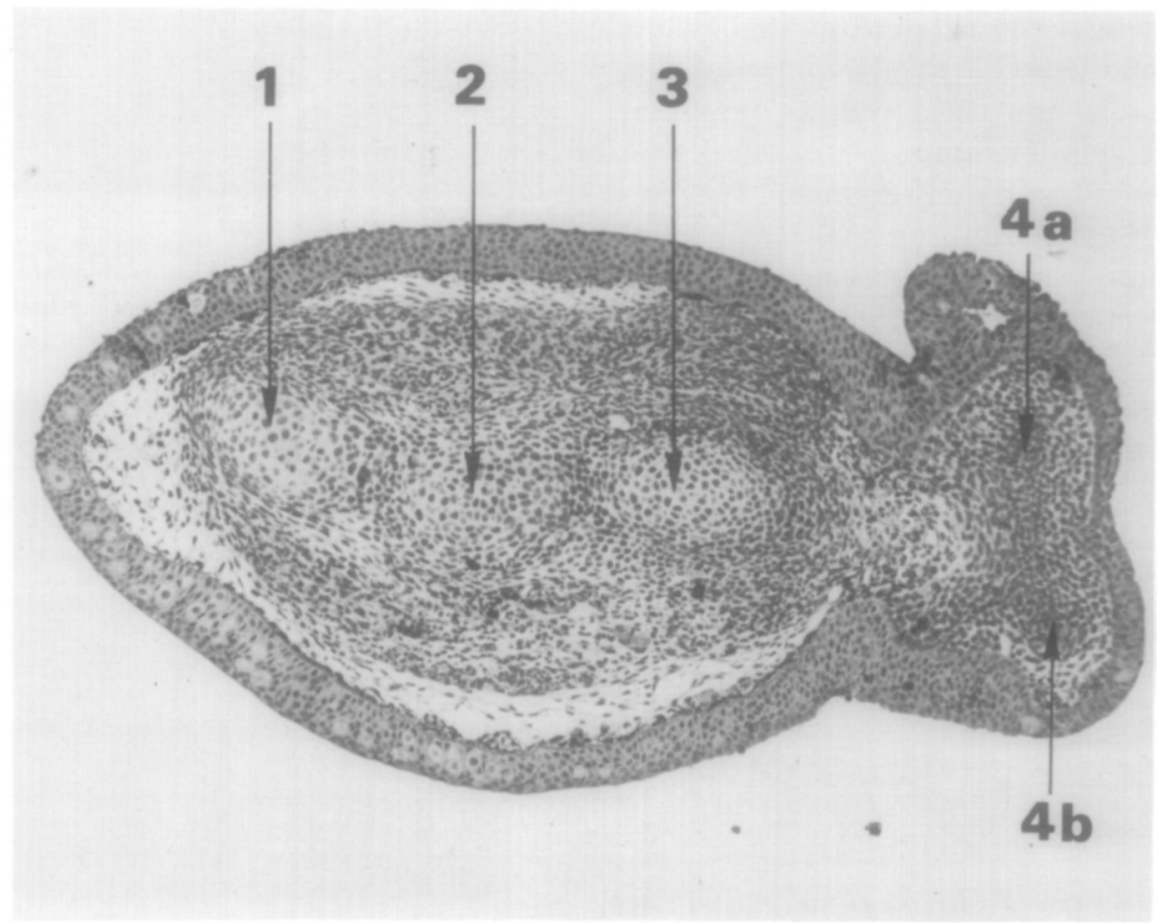

FIG. 22. Cross section through early regenerate of the type illustrated in Fig. 18C. The fourth digit is duplicated. $\mathbf{H}+\mathbf{E}$. 
morphogenetic information within the regenerating limb as revealed by experiments that have produced multiple regenerates after rotation of tissue components within the limb stump. At this point, neither the nature of the information nor its role in determining the form of the normal limb regenerate is clear. The information can still be most accurately described as "the morphogenetic information that causes multiple limbs to form after rotation or positional displacement of stump tissues."

The formation of multiple regenerates rather than single regenerates with axial reversals corresponding to that of the rotated stump skin logically suggests that the skin is not the sole component of the stump capable of expressing the morphogenetic information demonstrated in these experiments. This was the basis for originally characterizing the multiple regeneration as the manifestation of a morphogenetic conflict within the limb stumps. Therefore it is not surprising that rotation of stump muscle beneath normally oriented skin (Lheureux, 1972; this report) also results in multiple regeneration.

More surprising was the inability of rotated or positionally displaced bone to influence morphogenesis. Cells from the skeleton are commonly considered to participate in the formation of the regeneration blastema, and their importance is emphasized in experiments involving the restoration of regenerative ability of X-rayed limbs by grafts of cartilage (Eggert, 1966; Wallace et al., 1974). One insufficiently tested possibility is that against the background of the large numbers of muscle, connective tissue and skin cells, the skeleton is quantitatively unable to influence morphogenesis to the extent of causing limb abnormalities. Rotation of bones in limbs from which the musculature has been surgically removed might allow the expression of any latent morphogenetic potential in the skeleton. Another intriguing possibility is that in the regenerating limb, the form of the skeleton is wholly a product of morphogenetic influences residing elsewhere in the limb and that the stump skeleton may contribute little beside cells to the regenerate. In view of the early differentiation of the skeleton in the regenerating limb and the results of some of the older work on bone transplantation to heterotopic limb stumps (rev. by Vorontsova, 1949; Goss, 1961), a purely passive role of the skeleton is unlikely although conceivably the skeleton could be deficient in the specific morphogenetic property demonstrated here.

The dermis of the stump is clearly a major repository of morphogenetic information whereas the epidermis of the stump either contains little, if any, of the information or is incapable of expressing the information that it might have. It must be emphasized, however, that the ability of the epidermis over the regeneration blastema to influence morphogenesis might be considerably different from that of the epidermis covering the stump.

Thus at least in the axolotl, the dermis and muscle play a dominant morphogenetic role. At this point it is not possible to assign the morphogenetic influence of muscle to either the muscle fibers themselves or to the connective tissue component. The prominent role of the dermis in controlling the morphogenesis of a regenerating limb was emphasized for years by the school of Guyénot (Guyénot and Ponse, 1930; Guyénot et al., 1948; Droin, 1959), but its importance was carried to the point of implying that the dermis alone possessed morphogenetic potential and formed the regenerative blastema.

The experiments of both Lheureux (1972) and Carlson (this report) have shown that the morphogenetic influence of rotated skin is completely blocked if a thin cuff of normally oriented skin intervenes between the rotated skin and the amputation surface. This finding complements the early X-irradiation experiments of Butler (1935), who concluded that the primary 
source of cells making up a limb regenerate was the most distal 1-2 mm of stump tissues. Butler did not extend his conclusions to sources of morphogenetic control.

The ability of rotated skin $2-3 \mathrm{~mm}$ proximal to the amputation surface to exert some control over the morphogenesis of the regenerate in the absence of any intervening normally oriented skin (Fig. 10) illustrates that under some circumstances, proximally placed stump tissues can influence morphogenesis. A likely mechanism, however, is the carrying of morphogenetic information on cells that migrate distally from the more proximal rotated tissues. In that case direct morphogenetic control operating from a distance could be eliminated. Nevertheless the experimental data at hand do not allow one to rule out the blockage of some morphogenetic emanation from the proximal rotated skin. One cannot distinguish between these two options on the basis of the experiment summarized in Fig. 11 because the newly regenerated distal stump skin could block either the distal migration of dermal cells or a direct morphogenetic influence from the proximal rotated cuff. Solution of this problem will require experiments involving stable long term markers on cells of the rotated proximal stump skin.

All evidence indicates that the morphogenetic information in question is very stable and that the information requires an epimorphic regenerative response for its expression. When skin (Carlson, 1974) or intact muscles (Fig. 8) are rotated and allowed to heal in place for periods of several months to over 2 years, no abnormalities in the healing pattern are seen, and the formation of supernumerary limbs does not occur. Yet, upon amputation of the limbs through the rotated tissues, multiple regeneration occurs in percentages similar to that occurring after the amputation of limbs through freshly rotated tissues. This suggests either a very low turnover rate or a high degree of preservation of original instructions if the morphogenetic information is renewed.

The original morphogenetic information in cross-transplanted muscles is also retained after mincing, although the course of the subsequent tissue regenerative process does not differ from that of a muscle minced and replaced in situ (Carlson, $1975 \mathrm{~b})$. There is to date no evidence that a rotated or positionally dislocated tissue, either in a morphologically stable state or while it is undergoing tissue regeneration, can be reinstructed by its new site within the limb so that its morphogenetic information corresponds to that of the new site in which it has been placed. Nevertheless, limb amputation after the healing and tissue regenerative processes have stabilized leads to the formation of multiple regenerates. These experiments provide further evidence of major differences, in this case morphogenetic control, between the tissue and epimorphic modes of regeneration (Carlson, 1970).

Two studies (Rahmani and Kiortsis, 1961; Carlson, 1974) have conclusively demonstrated that X-radiation of a rotated tissue within a limb stump eliminates its capacity to stimulate the formation of multiple regenerates. Although it has been suggested (Trampusch, 1958a, b; Oberpriller, 1968) that X-radiation of a tissue eliminates its morphogenetic field properties, the nature of this influence remains unknown. The circumstantial evidence from several types of experiments, particularly those involving mincing or X-radiation of rotated tissues, strongly suggests that the morphogenetic information in question is in some manner bound to the cells themselves. It doesn't seem to depend upon the overall morphological integrity of the rotated tissues themselves.

Although both the normal embryonic limb bud (Harrison, 1918) and the regeneration blastema (Bryant and Iten, 1974; Stocum, 1975) have been shown to possess a well developed capacity for regulation, the 
mature stump tissues of the amputated limb exhibit morphogenetic properties more befitting of a mosaic system, at least with respect to the expression of information pertaining to their position along the A-P axis. Thus one can profitably consider the regenerating limb to be a system subject to two types and levels of morphogenetic control: a proximal stump demonstrating some characteristics of a mosaic system and a distal blastema that at some stages is highly regulative.

The regulative properties of the blastema, in addition to compensating for defects in or additions to the blastema itself, also compensate for deletions of specific tissue components from the stump, notably bone (Fritsch, 1911; Bischler, 1926; Thornton, 1938; Goss, 1956) and muscle (Carlson, 1972). Yet proximal to the sphere of influence of the epimorphic regenerative process, the deleted stump components are not faithfully replaced, with the possible exception of bones in extremely small larvae.

Despite its regulative ability, the regeneration blastema seems incapable of completely erasing misinformation provided by the stump. Multiple regeneration is the common result. In addition to the many demonstrations of multiple regeneration appearing after the rotation of stump tissue components, additional evidence has been provided by Iten and Bryant (1975). They transplanted left blastemas onto right limbs, with the discordance between blastema transplant and stump being along the A-P axis. When the blastemal transplants were of certain ages, high percentages of multiple regenerates were formed. The later experiment is similar to the $180^{\circ}$ rotations that have been performed on wing buds of chick embryos (Saunders et al., 1958; Amprino, 1962, 1968), but the arrangement of the resulting duplications in the wing differs from that of the multiple regenerates.

The nature of the morphogenetic infor- mation demonstrated by these experiments remains almost wholly unknown, but it now seems certain that the information is in some manner both a record and expression of the original position within the limb of the tissue bearing it. More specifically, in the axolotl, at least, the information seems to be a record of the position of the tissue along the A-P axis of the limb (Carlson, 1974). There is little evidence in favor of major expressible information content recording the position of the tissue along the $\mathrm{D}-\mathrm{V}$ axis in the upper arm of the axolotl. However, the findings of Settles (1970) in T. viridescens and Lheureux (1972) in Pleurodeles waltlii suggest that there may be species differences in the presence and/or amount of positional information along the $\mathrm{D}-\mathrm{V}$ axis of the limb.

There is a remarkably close parallel between the types of surgical manipulations that lead to the formation of multiple limb regenerates in the adult axolotl and those that result in the appearance of multiple limbs during ontogeny in larval Ambystoma. During their investigations on the determination of axes and limb symmetry in Ambystoma larvae, Harrison and his school (1921; Hollinshead, 1932; Swett, 1927,1940 ) consistently found that many of their experiments were complicated by the formation of multiple limbs. The experiments in which multiple limbs were formed were those in which forelimb buds, after their A-P axes were determined, were rotated either homopleurally or heteropleurally, so that the A-P axis alone or in combination with another, was reversed between the limb bud and the body of the animal. Multiple limbs did not form when the D-V axis alone was reversed. Although the possibility that the formation of multiple limbs was due solely to positional changes of components of the limb stump with respect to the body was considered (Harrison, 1921), it was apparently not adequately tested. Instead, the formation 
of multiple limbs was related to the axial rotation and symmetry of the limb primordium with respect to the body. It would not be surprising if multiple limbs in larvae could be stimulated by exchanging anterior and posterior halves of limb primordia in a manner analogous to that in the experiment illustrated in Fig. 17.

The experiments performed on this experimental system have established the existence of a very stable array of information that appears to encode the position of cells along the A-P axis of the limb. In muscle and dermis this information is readily expressed when these tissues are displaced along the A-P axis of the limb stump. The positional information seems so stable that it persists throughout the mincing and subsequent tissue regeneration of limb muscles (Carlson, 1975b). A major question to be answered is whether this information persists throughout the phase of morphological dedifferentiation of cells during the early blastemal phase of limb regeneration or whether during the dedifferentation and early blastemal phases of normal limb regeneration the positional information is also erased and subsequently reconstituted. Neither the mechanism by which the positional information is established during ontogeny nor the means by which it is maintained in the adult limb have been investigated.

Experiments performed to date provide no evidence in favor of active gradients that supply or maintain positional values in the mature limb (Carlson, unpublished). In addition, the anatomical complexity and widely varying types of tissues making up the limb's cross-section are not favorable for supporting a smooth active gradient. It is possible, however, that information from an active embryonic gradient was cemented in place as the tissues of the limb differentiated. It remains to be shown whether or not an A-P gradient supplies positional information in the more homogeneous limb bud as Wolpert $(1969,1971)$ and others (Summerbell et al., 1973) have sug- gested with respect to the outgrowth of appendages. Assigning the formation of the multiple regenerates to disturbances in symmetry relationships is unlikely to shed much light upon mechanisms until the factors determining symmetry are more concretely defined.

One way of looking at the positional information and its expression is to assume that along the A-P axis of the upper arm there is a large number of points, probably equal to or less than the number of subepidermal cells distributed along that axis in any dorsoventral plane of the limb cross section. Each point codes for a particular unit of morphogenetic information (Fig. 23, Part 1), and in the mature limb each point is independent of any other unit(s) of information at other points for its expression or maintenance. When a mass of tissue within the limb is positionally dislocated, it retains its original positional values (Fig. 23, Parts 2, 3). The positional information along the A-P axis of the stump would have to be transmitted to the outgrowing blastema in some manner, either by a cellular contribution or some other means of information transfer (Fig. 24 ), and the areas of the blastema receiving this information would each then take form according to the particular type of positional information that they received. The information transfer would occur in a large number of $\mathrm{D}-\mathrm{V}$ planes within the blastema. Two models of information transfer seem possible at this time. According to one (Fig. 24, Part 2A), positional information along the A-P axis of the blastema is determined entirely by the stump. According to the other (Fig. 24, Part 2B), the blastema (probably after receiving initial cues from the stump) generates or maintains intrinsic A-P positional information, which is in turn influenced by the abnormal positional messages emanating from the dislocated tissues within the stump. Hints from a number of experiments in the older regeneration literature lead me to favor the latter model. It as- 

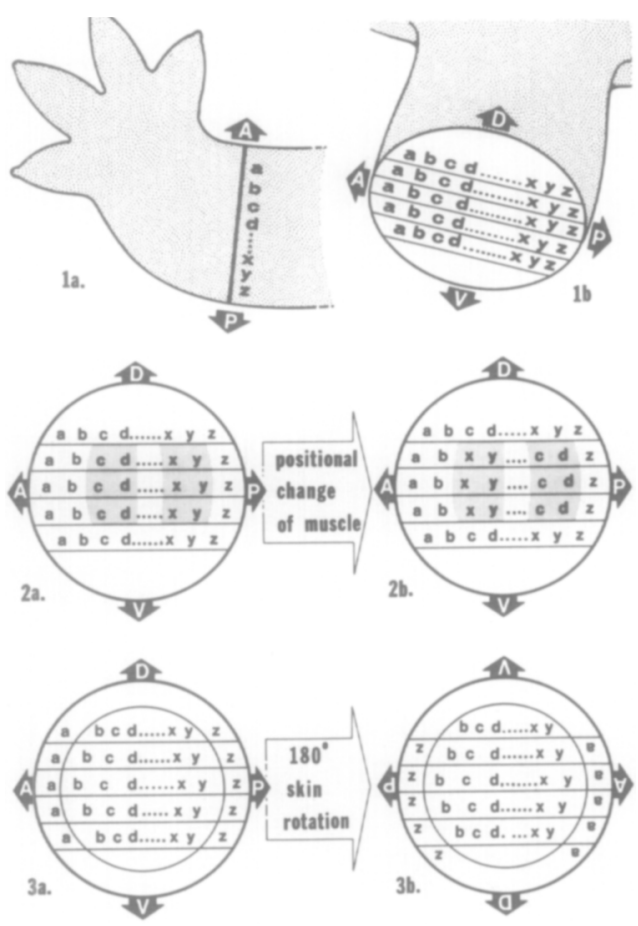

Fig. 23. (1a, b), Longitudinal and cross-sectional representations of a postulated encoding of positional information along many planes of the A-P axis of the upper arm. (2a, b), Schematic crosssectional representation of the effects of cross-transplantation of muscles with respect to their positional information. The stippled " $x, y$ " area represents the extensor muscle and the "c,d" area, the flexor muscle. $(3 a, b)$, Schematic cross-sectional representation of the effects of $180^{\circ}$ rotation of the skin (outer circle) around the underlying limb tissues. In all these diagrams the lower-case letters represent hypothetical units of positional information. A, anterior; $\mathrm{P}$, posterior; $\mathrm{D}$, dorsal; $\mathrm{V}$, ventral.

sumes that within the blastema the disparities in positional information are not always sorted out; otherwise perfectly normal regenerates would result. Variations in the complexity of the regenerates could be due to several factors, such as partial sorting out of the scrambled positional information along the various $D-V$ planes or differences in the degree of harmonious integration at the interfaces between parts of the blastema derived from normal and from positionally dislocated regions of the stump.

This proposed type of mechanism could also provide a basis for looking at other morphogenetic disturbances in regeneration, such as the reversal of symmetry in regenerates arising from proximodistally reversed stumps (Butler, 1951; Dent, 1954; Deck, 1955; Carlson et al., 1974) (Fig. 25).

Very little is yet know about either the timing or the pathway of transmission of the morphogenetic information in these experiments. The first unequivocal evidence of multiple regeneration is the appearance of the triaxial or otherwise abnormal apical ridge at the time when the cone blastema begins to flatten. The abnormal ridge seems to be a key factor in understanding the nature of the morphogenetic disturbances because the digits of the multiple regenerates invariably form along the ridges. In fact, with experience it has become possible to predict the general morphological type and complexity of the multiple regenerate from the configuration of the apical ridge. Although there is a close correlation between the abnormal apical ridge and the subsequent formation of digits, we can not yet say whether or not it is merely a morphological indicator of impending digit formation. At present neither its morphology nor its function can be equated with the apical ridge of embryonic limbs of birds and mammals, but current work is underway in an attempt to define further the role of this structure in regeneration.

Even without an exact knowledge of its function, one can make some general inferences on the basis of the geometrical arrangement of the apical ridges. In the triaxial configuration, particularly the case where there are two major limbs and one minor one within the ridge (Fig. 18B), it is apparent that each major limb represents the bulk of a hand-forming territory and that the minor limb represents an area shared by the two major hand-forming territories. The degree of sharing varies, and it ultimately determines the amount of overlap of the multiple digits and hands. These relationships, so appar- 


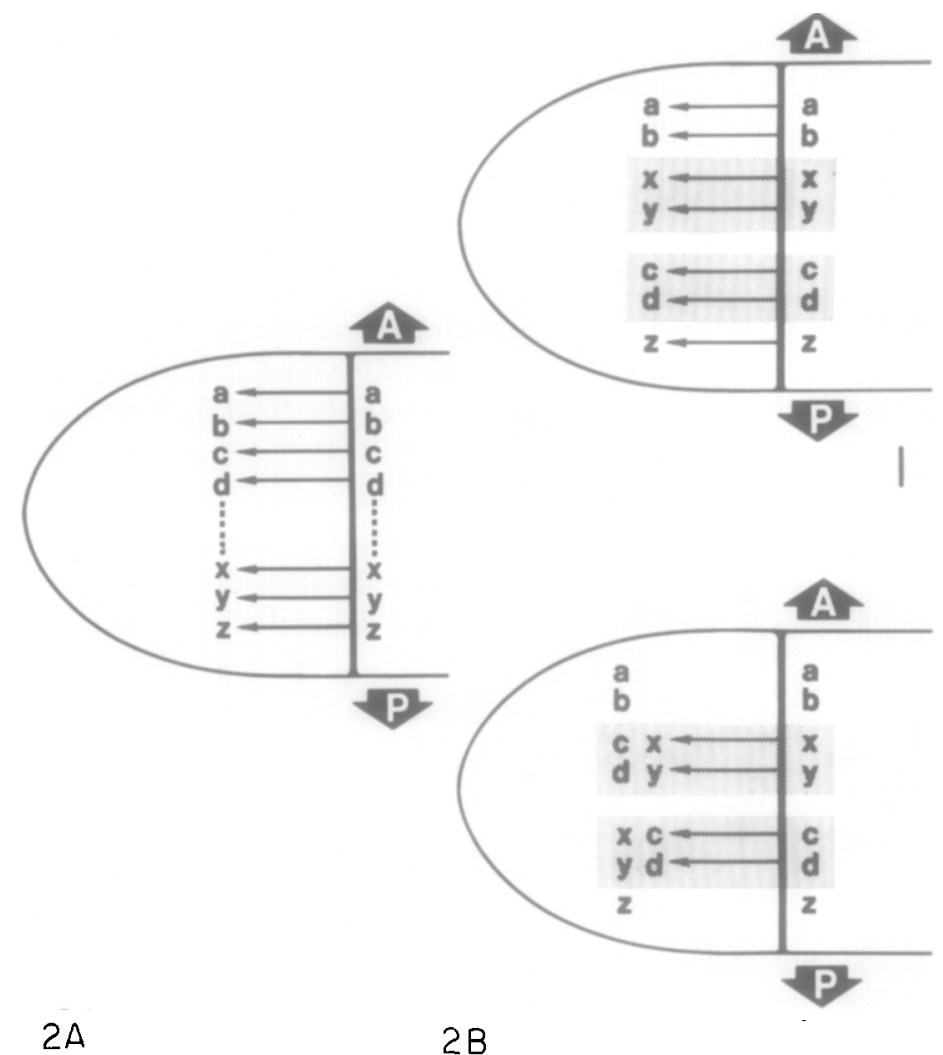

Fig. 24. Transmission of positional information from limb stump to regeneration blastema. (1), Normally regenerating limb. There is a point-for-point correspondence of position between stump and blastema. The mechanisms accounting for this correspondence are unknown. (2A, B), Two models of information transfer that could account for the morphogenetic conflict occurring in regenerates arising from stumps bearing cross-transplanted muscles. (2A), Positional information along the A-P axis of the regenerate is specified entirely on the basis of instructions received from stump tissues. (2B), self-generating array of A-P positional information within the blastema with a superimposed influence from the positionally dislocated muscles of the stump. Regions subjected to two different kinds of positional messages (e.g., $c-x, d-y)$ become sites of morphogenetic instability and generate duplications within the regenerate.

ent during the earliest stages of digit formation, are often very difficult to discern when looking at gross specimens of mature regenerates. The situation is often further complicated by the concurrent duplications of individual digits within the multiple regenerates.

The fact that the angle between the minor and each major limb of a triaxial ridge is roughly the same (although this angle may differ from one triaxial ridge to the next) suggests that each major ridge, or the territory it represents, possesses some mechanism for excluding or spacing the other territory and that in most cases each exerts a roughly similar effect. Otherwise one would expect to see more cases in which the minor limb of the ridge is closer to one major ridge than the other. At this point it has not been possible to relate any particular configuration of the apical ridge to the type of tissue rotation or transposition within the limb stump. Without additional experimental data, further speculation on the ridge at this point becomes progressively less profitable.

At present we possess only indirect information about the timing of transmission of the morphogenetic information leading to multiple regeneration. Evidence from mor- 

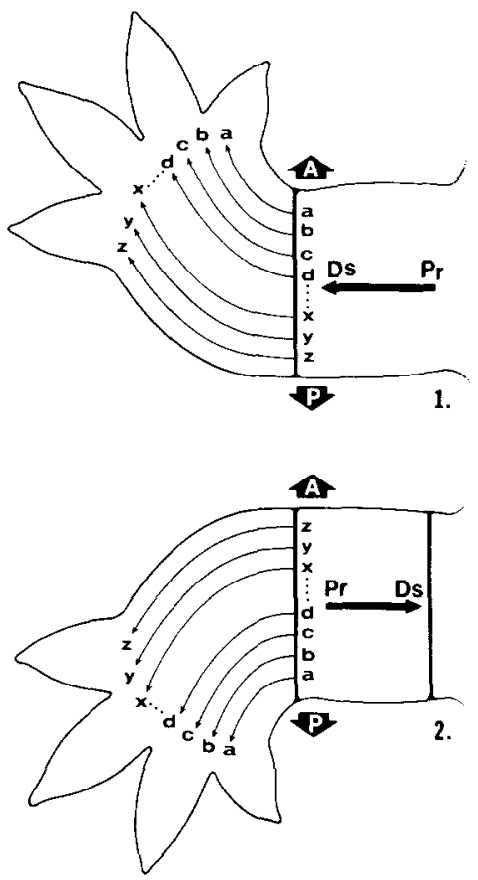

Frg. 25. Hypothetical mechanism that would explain the reversal of A-P symmetry in regenerates arising from proximodistally reversed stumps on the basis of a point-for-point correspondence between bits of positional information along the A-P axis of the stump and regenerate. This scheme is similar to those proposed by Bryant (1971) and Wolpert (1971) except that the reversal of symmetry need not necessarily be tied to a gradient as their diagrams suggest. (1), Normal regenerate. (2), Regenerate arising from stump with reversed Pr-Ds polarity.

phology alone (Carlson, 1974) suggests that the information can be transmitted over a relatively long period rather than as a trigger-type release of information at a definite and restricted period of time. Preliminary experimentation (Glidden and Carlson, unpublished) shows no evidence of the permanent transmission of morphogenetic information between the time of amputation and the late phase of dedifferentiation. The recent work of Iten and Bryant (1975) shows that multiple regeneration in newts can be stimulated when blastemas of various ages are transplanted with reversal of the A-P axis relative to that of the stump of the host limb. Their work indicates that the morphoge- netic information can be transmitted over much of the period of the blastema, but that the information is processed differently by blastemas of different ages.

Despite our vast ignorance of the factors that control the form of almost all developing systems and the frustrating slowness with which clues are found, the reawakening of interest in morphogenesis of the regenerating limb in several laboratories has recently produced several promising experimental models. Although none of these has been refined or tested to the point of being able to explain morphogenetic phenomena on molecular or even cellular terms, the ability to predict abnormal developmental events on the basis of these models leads one to expect that this experimental and theoretical approach will ultimately bring us to a more complete and satisfying understanding of morphogenesis.

The author wishes to thank Mr. William Brudon for the artwork and gross photography.

\section{REFERENCES}

Amprino, R. (1962). Aspetti della morforgenesi delle estremita nei vertebrati. Monit. Zool. Ital. (Suppl.) 70-71, 7-130

Amprino, R. (1968). On the causality of the distal twinning of the chick embryo wing. Arch. Biol. 79, 471-503.

Bischler, V. (1926). L'influence du squelette dans la régénération, et les potentialités des divers terri. toires du membre chez Triton cristatus. Rev. Suisse Zool. 33, 431-559.

Bryant, P. J. (1971). Regeneration and duplication following operations in situ on the imaginal discs of Drosophila melanogaster. Develop. Biol. 26, 637-651.

Bryant, S. V., and Iten, L. E. (1974). The regulative ability of the limb regeneration blastema of Notophthalmus viridescens: Experiments in situ. Roux Archiv 174, 90-101.

Butler, E. G. (1935). Studies on limb regeneration in X-rayed Amblystoma larvae. Anat. Rec. 62, 295-307.

Butler, E. G. (1951). The mechanics of blastema formation and regeneration in urodele limbs of reversed polarity. Trans. N.Y. Acad. Sci. 13, 164167.

Carlson, B. M. (1970). Relationship between the tissue and epimorphic regeneration of muscles. 
Amer. Zool. 10, 175-186.

Cartson, B. M. (1972). Muscle morphogenesis in axolotl limb regenerates after removal of stump musculature. Develop. Biol. 28, 487-497.

CarLson, B. M. (1974). Morphogenetic interactions between rotated skin cuffs and underlying stump tissues in regenerating axolotl forelimbs. Develop. Biol. 39, 263-285.

Carlson, B. M. (1975a). The effects of rotation and positional change of stump tissue upon morphogenesis of the regenerating axolotl limb (abstr.) Anat. Rec. 181, 325.

Carlson, B. M. (1975b). Multiple regeneration from axolotl limb stumps bearing cross-transplanted minced muscle regenerates. Develop. Biol. 45, 203-208.

Carlson, B. M., Civiletto, S. E., and Goshgarian, H. G. (1974). Nerve interactions and regenerative processes occurring in newt limbs fused end-toend. Develop. Biol. 37, 248-262.

DECK, J. D. (1955). The innervation of urodele limbs of reversed proximo-distal polarity. J. Morphol. 96, 301-331.

DENT, J. N. (1954). A study of regenerates emanating from limb transplants with reversed proximodistal polarity in the adult newt. Anat. Rec. 118, $841-856$.

Droin, A. (1959). Potentialités morphogenes dans la peau du Trition en régénération. Rev. Suisse Zool. 66, 641-709.

EgGert, R. C. (1966). The response of X-irradiated limbs of adult urodeles to autografts of normal cartilage. J. Exp. Zool. 161, 369-390.

Fritsch, C. (1911). Experimentelle Studien über Regenerations vorgänge des Gliedmassenskelets der Amphibien. Zool. Jahrb. 30, 377-472.

GLADE, R. (1957). The effects of tail tissue on limb regeneration in Triturus viridescens. J. Morphol. $101,477-522$.

Goss, R. J. (1956). The relation of bone to the histogenesis of cartilage in regenerating forelimbs and tails of adult Triturus viridescens. J. Morphol. 89, 98-124.

Goss, R. J. (1961). Regeneration of vertebrate appendages. Adv. Morphog. 1, 103-152.

Guyénot, E., Dinichert-Favarger, J., and GalLAND, M. (1948). L'exploration du territoire de la patte antérieure du Triton. Ref. Suisse Zool. 55 (Suppl. 2), 1-120.

Guyénot, E., and Ponse, K. (1930). Territories de régénération et transplantations. Biol. Bull. Fr. Belg. 64, 251-287.

Harrison, R. G. (1918). Experiments on the development of the forelimb of Amblystoma, a self-differentiating equipotential system. J. Exp. Zool. 25, 413-461.

Harrison, R. G. (1921). On relations of symmetry in transplanted limbs. J. Exp. Zool. 21, 1-136.
Hollinshead, W. H. (1932). Determination of potencies in the forelimb of Amblystoma punctatum. $J$. Exp. Zool. 63, 457-482.

Iten, L. E., and Bryanr, S. V. (1975). The interaction between the blastema and stump in the establishment of the anterior-posterior and proximodistal organization of the limb regenerate. $D e-$ velop. Biol. 44, 119-147.

Lheureux, E. (1972). Contribution à l'étude du rôle de la peau et des tissus axiaux du membre dans le déclenchement de morphogenèses régénératrices abnormales chez le triton Pleurodeles waltlii Michah. Ann. Embryol. Morphog. 5, 165-172.

Oberpriller, J. (1968). The action of X-irradiation on the regeneration field of the forelimb of the adult newt, Diemyctylus viridescens. J. Exp. Zool. $168,403-422$.

Rahmani, T. (1960). Conflit de potentialitiés morphogènes et duplicature. Rev. Suisse Zool. 67, 589-675.

Rahmani, T., and Kiortsis, V. (1961). Le rôle de la peau et des tissus profonds dans la régénération de la patte. Rev. Suisse Zool. 68, 91-102.

Saunders, J. W., Gasseling, M. T., and Gfeller, M. D. (1958). Interactions of ectoderm and mesoderm in the origin of axial relationships in the wing of the fowl. J. Exp. Zool. 137, 39-74.

SETTLES, H. E. (1967). Supernumerary regeneration caused by ninety degree skin rotation in the adult newt, Triturus viridescens. Ph.D. thesis, $44 \mathrm{pp}$. Tulane University, New Orleans.

Settles, H. E. (1970). Morphogenetic effects of limb skin during limb regeneration in the adult newt, Triturus viridescens. (Abstract). Anat. Rec. 166, 375.

Stocum, D. L. (1975). Regulation after proximal or distal transposition of limb regeneration blastemas, and determination of the proximal boundary of the regenerate. Develop. Biol. 45, 112-136.

Summerbell, D., Lewis, J. H., and Wolpert, L. (1973). Positional information in chick limb morphogenesis. Nature (London) 244, 492-496.

SwETT, F. H. (1927). Differentiation of the amphibian limb. J. Exp. Zool. 47, 385-439.

SwETT, F. H. (1940). Experiments upon the initiation of reduplication in the embryonic limb rudiment of Amblystoma punctatum (Linn.). J. Exp. Zool. 85, 431-436.

Thornton, C. S. (1938). The histogenesis of the regenerating fore limb of larval Amblystoma after exarticulation of the humerus. J. Morphol. 62, 219-242.

Trampusch, H. A. L. (1958a). The action of X-rays on the morphogenetic field. I. Heterotopic grafts on irradiated limbs. Proc. Kon. Ned. Akad. Wetensch. Ser. C. 61, 417-430.

Trampusch, H. A. L. (1958b). The action of X-rays on the morphogenetic field. II. Heterotopic skin on 
irradiated tails. Proc. Kon. Ned. Akad. Wetensch. Ser. C. 61, 530-545.

Vorontsova, M. A. (1949). Regeneration of Organs in Animals (Russian), pp. 206-210. Sovietskaya Nauka, Moscow.

Wallace, H., Maden, M., and Wallace, B. M. (1974). Participation of cartilage grafts in amphibian limb regeneration. J. Embryol. Exp. Morphol.
32, 391-404.

Wolpert, L. (1959). Positional information and the spatial pattern of cellular differentiation. $J$. Theoret. Biol. 25, 1-47.

Wolpert, L. (1971). Positional information and pattern formation. Curr. Top. Develop. Biol. 6, 183224. 